\title{
Evidence-based support for the all-hazards approach to emergency preparedness
}

\author{
Bruria Adini ${ }^{1,2,34^{*}}$, Avishay Goldberg ${ }^{2,3}$, Robert Cohen ${ }^{1,2}$, Daniel Laor ${ }^{1,2}$ and Yaron Bar-Dayann 2,3
}

\begin{abstract}
Background: During the last decade there has been a need to respond and recover from various types of emergencies including mass casualty events (MCEs), mass toxicological/chemical events (MTEs), and biological events (pandemics and bio-terror agents). Effective emergency preparedness is more likely to be achieved if an all-hazards response plan is adopted.
\end{abstract}

Objectives: To investigate if there is a relationship among hospitals' preparedness for various emergency scenarios, and whether components of one emergency scenario correlate with preparedness for other emergency scenarios.

Methods: Emergency preparedness levels of all acute-care hospitals for MCEs, MTEs, and biological events were evaluated, utilizing a structured evaluation tool based on measurable parameters. Evaluations were made by professional experts in two phases: evaluation of standard operating procedures (SOPs) followed by a site visit. Relationships among total preparedness and different components' scores for various types of emergencies were analyzed.

Results: Significant relationships were found among preparedness for different emergencies. Standard Operating Procedures (SOPs) for biological events correlated with preparedness for all investigated emergency scenarios. Strong correlations were found between training and drills with preparedness for all investigated emergency scenarios.

Conclusions: Fundamental critical building blocks such as SOPs, training, and drill programs improve preparedness for different emergencies including MCEs, MTEs, and biological events, more than other building blocks, such as equipment or knowledge of personnel. SOPs are especially important in unfamiliar emergency scenarios. The findings support the adoption of an all-hazards approach to emergency preparedness.

Keywords: Emergency preparedness, Evidence-based, All-hazards approach, Evaluation, Mass casualty events

\section{Background}

During the last decade the need to respond to various emergencies such as natural disasters and technological and complex mass casualty events (MCEs) has increased [1]. While the nature of the events may differ significantly, preparedness for them appears to have much in common in terms of the knowledge and skills required $[2,3]$. Numerous mitigation programs have proven to be highly cost-effective in preparing for different types of crises [4].

\footnotetext{
* Correspondence: adini@netvision.net.il

${ }^{1}$ Emergency and Disaster Management Division, Ministry of Health, Tel Aviv, Israel

${ }^{2}$ PREPARED research center, Ben-Gurion University of the Negev, Beer-Sheva, Israel

Full list of author information is available at the end of the article
}

Effective preparedness of hospitals for different hazards is more likely to be achieved if healthcare professionals adopt an all-hazards response plan that applies generic basic principles for managing different scenarios [5-8]. The all-hazards approach contends that emergency preparedness requires attention not just to specific types of hazards but also to actions that increase preparedness for all risks $[7,8]$.

In view of these common components, the World Health Association (WHO) as well as other leaders in crisis management advocate the all-hazards approach as the recommended mechanism for emergency preparedness [9]. Nevertheless, the all-hazards policy has as yet not been fully adopted. Some experts support other programs such as utilization of risk assessment and

\section{Biomed Central}


reduction as a starting point for provision of goods and services based on needs assessment [10]. It has often been presented that capacity building programs focus on preparedness for a specific disaster; therefore, the legislation, administrative arrangements, and institutional structures are frequently created to respond to that scenario rather than to the common components that characterize different types of emergencies [11]. It has even been stated that despite lessons learned from disasters, increase in knowledge, and technological development, no shift in policy has been made with regard to crisis management [12].

Limited information is available with regard to what constitutes effective emergency preparedness; however, there is consensus that availability of a comprehensive Standard Operating Procedure (SOP), exercises and drills are important components in the preparedness process [13-15]. Implementation of realistic and wellrun drills is a complex task requiring significant resources in terms of cost, manpower, and time commitment; thus the number and extent of drills are limited [16-18]. It would seem that there is much to be gained from identifying principles and knowledge that are common to all preparedness programs; ignoring these similarities and differences may hinder effective inter-agency collaboration [19].

The importance of preparing the medical system to deal with different emergencies while attempting to contain costs, suggests that it would be advisable to determine if common components can be identified. To date the relationship among preparedness for different types of emergency events has not been well investigated $[8,20]$.

\section{Implementing an all-hazards approach in Israel}

The Israeli healthcare system adopted and maintains an all-hazards approach to emergency management, basing its policy on preparedness for mass casualty events [2]. All hospitals are instructed to utilize similar principles in preparing for MCEs, mass toxicological events (MTEs), and biological events, and modify only components that are hazard-specific such as utilizing isolation facilities in biological events or decontamination of casualties in a toxicological event. The main components that are implemented as the result of this policy include designation of similar admitting sites in different scenarios; assigning staff members (as much as possible) to the same site regardless of the type of emergency; applying similar principles for storing and allocating life-saving and supplementary equipment; preparing the infrastructure to be utilized in different crises; and integrating generic modules in the training programs for the different hazards.

As Israel has had to deal with numerous types of emergencies in the past ten years, including MCEs, man-made conflicts, and pandemics, its experience may shed light on the effectiveness of the all-hazards approach and contribute to other decision makers in setting the policy regarding emergency management.

The aim of this study was to investigate implementation of the all-hazards approach in order to identify: 1) if preparedness of hospitals to a specific emergency scenario relates to preparedness for other types of emergencies; and 2) relationships between specific components to the overall preparedness for various emergencies.

\section{Methods}

\section{Utilization of an evaluation tool to measure level of emergency preparedness}

An evaluation tool consisting of 490 measurable and objective parameters was developed through a comprehensive literature review and recommendations of content experts. Of the 490 parameters, 239 were common for all emergency scenarios; the additional 251 were scenariospecific to mass casualty events, mass toxicological events, or biological events $(67,78$, and 106 parameters, respectively). The content validity of the evaluation tool and the rate of importance of each parameter were determined through a modified Delphi process that included 229 content experts. Only parameters that were agreed upon by over $60 \%$ of the experts were included in the evaluation tool. The tool was tested in a pilot study conducted in two hospitals and, following its modification, evaluations were carried out by surveyors from the Ministry of Health and the Home Front Command. The evaluation process involved a review of the Standard Operating Procedures followed by a site visit during which all other components of the emergency preparedness were observed and measured. The overall score of readiness for emergencies was calculated utilizing a computer program that was specifically developed for this purpose, taking into account the level of importance of each parameter. The evaluation tool and its development were previously described [21] and were utilized to evaluate the level of emergency preparedness of all acute-care hospitals in Israel.

The 490 parameters, encompassing the various components of emergency preparedness, were classified into the following four categories:

1) Standard operating procedures (SOP) - based on national guidelines that were developed by the Ministry of Health $(\mathrm{MOH})$, each hospital is required to develop its own SOP for the various hazards;

2) Training and drills - according to the policy set by the $\mathrm{MOH}$, each hospital is required to conduct specific training programs and participate in both table-top exercises and full scale annual drills; 
3) Knowledge of staff - the level of required knowledge of staff regarding the different components of emergency response to the various hazards is determined by the $\mathrm{MOH}$;

4) Infrastructure and equipment - designated equipment essential for managing different hazards, such as ventilation machines, personal protective gear, vaccinations, and anti-viral drugs, must be procured to assure an effective emergency response. Similarly, vital infrastructure, such as decontamination sites or helipads, must be installed.

An example of parameters in each of the categories is presented in Table 1.

In addition to the evaluation tool, a random sample of approximately 30 physicians and nurses in each of the hospitals was given 56 standardized oral questions to evaluate their knowledge of the emergency preparedness process.

\section{Rating impact of each parameter on level of emergency preparedness}

The parameters were rated by the experts according to three levels of importance. Level A indicated parameters with a high impact on emergency preparedness (representing $60 \%$ of the total preparedness score). Level B indicated parameters with a medium impact (representing $30 \%$ of the total score). Level $\mathrm{C}$ indicated parameters with the lowest impact (representing 10\% of the total score). Mean rating scores for each parameter were calculated. The parameters were then classified according to four categories of emergency preparedness: SOPs, training and drills, infrastructure and equipment, and knowledge of staff.

\section{Evaluating levels of emergency preparedness in hospitals} The level of emergency preparedness was evaluated in 24 general hospitals in Israel, utilizing the evaluation tool by a team of 16 professional experts in emergency management from the $\mathrm{MOH}$ and the Home Front Command (HFC). Each component was evaluated by at least two raters, independently, and at the end of the evaluation process, the inter-rater reliability was calculated by comparing the findings of the two raters.

The evaluation process involved two phases: 1) an evaluation of the SOPs of the hospitals for MCE, MTE, and biological events prior to a site visit; and 2) a site visit by an evaluation team, at which time the remaining components for emergency preparedness were evaluated.

\section{Comparing levels of emergency preparedness to the various scenarios}

The results of the hospital evaluations for the different scenarios were analyzed using an in-house computer program that was developed specifically to calculate a score for the level of preparedness. This score was calculated by

Table 1 Examples of parameters in each of the four categories

\begin{tabular}{|c|c|c|c|}
\hline Number & Category & Type of emergency & Parameter \\
\hline \multirow[t]{3}{*}{1} & \multirow{3}{*}{$\begin{array}{l}\text { Standard Operating } \\
\text { Procedures (SOPs) }\end{array}$} & Mass casualty event & The SOP for mass casualty events is updated for the last year \\
\hline & & Mass toxicological event & $\begin{array}{l}\text { The hospital identified a decontamination team that will be } \\
\text { deployed to the immediate site }\end{array}$ \\
\hline & & Biological event & $\begin{array}{l}\text { The biological SOP includes a section regarding treatment } \\
\text { of medical bio-hazard waste }\end{array}$ \\
\hline \multirow[t]{3}{*}{2} & \multirow[t]{3}{*}{ Training \& drills } & Mass casualty event & $\begin{array}{l}80 \% \text { of the surgical staff reinforcing the Emergency } \\
\text { Department are graduates of an ATLS (advanced trauma } \\
\text { life support) course }\end{array}$ \\
\hline & & Mass toxicological event & $\begin{array}{l}70 \% \text { of the emergency department staff participated in a } \\
\text { designated mass toxicological event training program }\end{array}$ \\
\hline & & Biological event & $\begin{array}{l}\text { The hospital defined the medical staff that are required to } \\
\text { participate in the biological training program }\end{array}$ \\
\hline \multirow[t]{3}{*}{3} & \multirow[t]{3}{*}{ Knowledge of staff } & Mass casualty event & $\begin{array}{l}\text { The "nurse in charge" is proficient in using the public } \\
\text { address system }\end{array}$ \\
\hline & & Mass toxicological event & $\begin{array}{l}\text { More than } 85 \% \text { of the emergency department's nursing } \\
\text { staff passed a toxicological test with scores }>90\end{array}$ \\
\hline & & Biological event & $\begin{array}{l}\text { The emergency department physicians are proficient in } \\
\text { the mechanism of sending samples to the microbiology } \\
\text { laboratory }\end{array}$ \\
\hline \multirow[t]{3}{*}{4} & \multirow[t]{3}{*}{$\begin{array}{l}\text { Infrastructure \& } \\
\text { equipment }\end{array}$} & Mass casualty event & $\begin{array}{l}\text { The "immediate site" for treating severe casualties is } \\
\text { equipped with a cart designated for treating children }\end{array}$ \\
\hline & & Mass toxicological event & $\begin{array}{l}\text { At least } 15 \text { personal protection masks are immediately } \\
\text { available in the emergency department }\end{array}$ \\
\hline & & Biological event & $\begin{array}{l}\text { Designated sites for isolating patients suffering from } \\
\text { infectious diseases have been defined }\end{array}$ \\
\hline
\end{tabular}


multiplying the level of performance identified for each parameter (satisfactory performance allotted the maximal points; needing minor revisions allotted 70\%; needing major revisions allotted 30\%; while unsatisfactory performance allotted 0 points) by the relative value of the parameter (each Level A parameter was worth $0.57 \%$ of the overall score; each Level B parameter was worth $0.17 \%$; and each Level $C$ was worth $0.05 \%$ of the overall score). The points achieved for each parameter were summed in order to calculate the overall score of the hospital. The score for the level of emergency preparedness for each scenario was also analyzed in relation to each category: SOPs, training and drills, infrastructure and equipment, and knowledge of personnel.

\section{Statistical analysis}

Data were analyzed using SPSS 15 (SPSS Inc., 2006). The preparedness scores of the hospitals were analyzed using the Spearman rho correlation coefficient, as follows: 1) Correlation of preparedness score for the different emergency scenarios (MCE, MTE, and biological events); 2) Correlation of scores in each category to the total preparedness score for the different emergency scenarios.

Correlation coefficients were defined as follows: rho $=$ $0.25-0.44$ - weak correlation; rho $=0.45-0.60-$ moderate correlation; rho $0.61-0.80$ - strong correlation, and $0.81-1.00$ very strong correlation. Each level of correlation is regarded as statistically meaningful if $p<0.05$.

\section{Results}

Relationship between overall hospital preparedness score for different emergency scenarios

The overall preparedness scores of the hospitals for MCE, MTE, and biological events ranged from 32 to
100. The average preparedness scores and standard deviations for the different types of emergency scenarios are presented in Figure 1. Inter-rater reliability was high, ranging from $95.3 \%$ to $99.2 \%$.

Medium relationships were found between the preparedness scores of the hospitals for the different emergency scenarios, as follows: 1 ) between MCE and MTE (.548, $p=0.006) ; 2)$ between MCE and a biological event (.541, $p=.009)$; and between MTE and a biological event $(.458, p=.032)$.

\section{Relationships between categories to total hospital} preparedness score for the various emergency scenarios Table 2 presents the correlations between preparedness of specific categories for each scenario with both overall preparedness for that scenario and overall preparedness for other emergency scenarios.

\section{SOPs}

Surprisingly, preparedness of SOPs for MCE was not found to be related to overall preparedness for that same scenario - MCE. Equally surprisingly, SOPs for MCE were found to be moderately related to preparedness for a different scenario - MTE. Preparedness of SOPs for MTE strongly correlated with preparedness for MTE, but did not correlate with preparedness for other emergency scenarios. Preparedness of SOPs for biological events strongly correlated with preparedness for a biological event, moderately correlated with preparedness for MTE, and weakly correlated with MCEs.

\section{Training and drills}

A strong to very strong relationship was found between training and drills and the total preparedness score

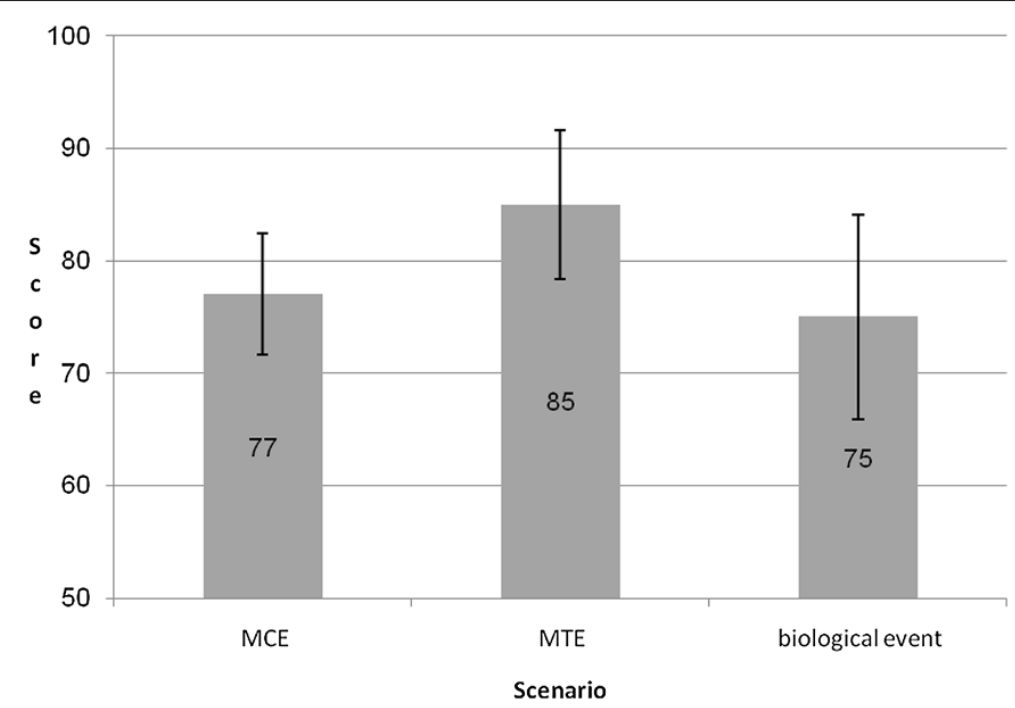

Figure 1 Average overall preparedness scores of all general hospitals for different emergency scenarios. 
Table 2 Relationship between specific components and the total emergency preparedness score for different emergency scenarios

\begin{tabular}{|c|c|c|c|}
\hline Category & $\begin{array}{l}\text { Emergency } \\
\text { preparedness } \\
\text { to MCE }\end{array}$ & $\begin{array}{l}\text { Emergency } \\
\text { preparedness } \\
\text { to MTE }\end{array}$ & $\begin{array}{l}\text { Emergency } \\
\text { preparedness } \\
\text { to biological } \\
\text { event }\end{array}$ \\
\hline \multicolumn{4}{|l|}{ SOP } \\
\hline \multirow[t]{2}{*}{ SOPs for MCE } & \multirow[t]{2}{*}{$p>.05$} & rho $=.581$ & \multirow[t]{2}{*}{$p>.05$} \\
\hline & & $p=.05$ & \\
\hline \multirow[t]{2}{*}{ SOPs for MTE } & \multirow[t]{2}{*}{$p>.05$} & rho $=.667$ & \multirow[t]{2}{*}{$p>.05$} \\
\hline & & $p=.001$ & \\
\hline \multirow{2}{*}{$\begin{array}{l}\text { SOPs for biological } \\
\text { event }\end{array}$} & rho $=.436$ & rho $=.480$ & rho $=.854$ \\
\hline & $p=.048$ & $p=.028$ & $p=.000$ \\
\hline \multicolumn{4}{|l|}{ Training/Drills } \\
\hline \multirow{2}{*}{$\begin{array}{l}\text { Training \& drills } \\
\text { for MCE }\end{array}$} & rho $=.702$ & rho $=.539$ & rho $=.572$ \\
\hline & $p=.000$ & $p=.012$ & $p=.007$ \\
\hline \multirow{2}{*}{$\begin{array}{l}\text { Training \& drills } \\
\text { for MTE }\end{array}$} & $\mathrm{rho}=.519$ & rho $=.844$ & rho $=.524$ \\
\hline & $p=.019$ & $p=.000$ & $p=.018$ \\
\hline \multirow{2}{*}{$\begin{array}{l}\text { Training \& drills for } \\
\text { biological events }\end{array}$} & rho $=.516$ & rho $=.437$ & rho $=.934$ \\
\hline & $p=.017$ & $p=.047$ & $p=.000$ \\
\hline \multicolumn{4}{|l|}{ Knowledge } \\
\hline \multirow{2}{*}{$\begin{array}{l}\text { Knowledge of } \\
\text { personnel } \\
\text { for MCE }\end{array}$} & rho $=.650$ & rho $=.619$ & rho $=.533$ \\
\hline & $p=.001$ & $p=.003$ & $p=.013$ \\
\hline $\begin{array}{l}\text { Knowledge of } \\
\text { personnel for MTE }\end{array}$ & $p>.05$ & $p>.05$ & $p>.05$ \\
\hline \multirow{2}{*}{$\begin{array}{l}\text { Knowledge of } \\
\text { personnel for } \\
\text { biological events }\end{array}$} & rho $=.439$ & $p>.05$ & $p>.05$ \\
\hline & $p=.047$ & & \\
\hline \multicolumn{4}{|l|}{ Infrastructure } \\
\hline $\begin{array}{l}\text { Infrastructure \& } \\
\text { equipment for MCE }\end{array}$ & $p>.05$ & $p>.05$ & $p>.05$ \\
\hline \multirow{2}{*}{$\begin{array}{l}\text { Infrastructure \& } \\
\text { equipment for MTE }\end{array}$} & \multirow[t]{2}{*}{$p>.05$} & rho $=.749$ & \multirow[t]{2}{*}{$p>.05$} \\
\hline & & $p=.000$ & \\
\hline \multirow{2}{*}{$\begin{array}{l}\text { Infrastructure \& } \\
\text { equipment for } \\
\text { biological events }\end{array}$} & rho $=.509$ & $N / S$ & rho $=.586$ \\
\hline & $p=.019$ & & $p=.05$ \\
\hline
\end{tabular}

for the emergency scenarios. Regardless of the type of training and drills that were conducted, their scores correlated not only with preparedness for the same specific type of emergency scenario, but also with preparedness for other types of emergency scenarios. The levels of correlations among training and drills to the various types of emergencies are presented in Table 2.

\section{Knowledge of staff}

Knowledge of healthcare personnel regarding MCE correlated with preparedness for all emergency scenarios: MCE, MTE, and a biological event. Knowledge of personnel regarding a biological event correlated only with preparedness for an MCE.

\section{Infrastructure and equipment}

No significant relationships were found between infrastructure and equipment for MCE and preparedness for different emergency scenarios. Infrastructure and equipment for MTE was strongly related with preparedness for MTE. A moderate relationship was found between infrastructure and equipment for a biological event and preparedness for both MCE and biological events.

\section{Discussion}

Based on theory alone and research prior to this study, one would not be able to conclude that preparedness for one scenario would enhance preparedness for other types of scenarios. At the same time, theory would suggest that there might be common components in the preparedness process for different emergency scenarios $[8,20]$. Given the fact that the process of preparing healthcare professionals to manage emergencies is both complicated and costly, it is important to optimize the emergency preparedness program by investing resources in the common components that may improve preparedness for different emergency scenarios [20, 22]. The all-hazards approach provides a standardized approach for emergency preparedness, while still tending to hazard-specific components [23].

\section{Relationship between preparedness for different emergency scenarios}

This study has shown that preparedness to a specific emergency is related to preparedness for other types of emergencies, thus strengthening the adoption of an allhazards policy $[2,9]$. It appears that when steps are carried out to prepare for one emergency scenario, this also influences the ability of the hospital to prepare for other types of scenarios. Nevertheless, there is a need to explore to what degree preparedness to one emergency enhances preparedness to other scenarios.

\section{Relationships among specific categories with the total preparedness score for different emergency scenarios}

It is a well-accepted assumption that a standard operating procedure is an essential requirement for emergency preparedness [2]. The findings of this study suggest that preparing an SOP might be especially important for scenarios for which hospital personnel are less well prepared or experienced [24]. A well-trained and experienced hospital staff may need to rely less on an SOP when dealing with a familiar emergency scenario, while in uncommon emergency scenarios, when the roles and expectations are less well known (as in mass toxicological events), a welldeveloped SOP is vital.

The relationship between knowledge related to MCE and preparedness for different types of scenarios would seem to suggest that there is a common hub of 
knowledge relevant to various emergency scenarios. The principles for managing an MCE seem to serve as the basis for other types of emergency preparedness programs [2], although scenario-specific knowledge must also be provided.

Training personnel and conducting drills are important factors of the emergency preparedness process in all scenarios [16]. Without the preparation of an SOP, provision of knowledge and capabilities to healthcare personnel, effective training, and drills, it is not possible for a hospital to achieve emergency preparedness [14, 17]. This assumption was strongly supported by the findings of this study.

Infrastructure and equipment were found to relate to the total preparedness score for an MTE and a biological event. This most probably is derived from the unique requirements that are specific to these scenarios, such as personal protective gear. Given that hospital staff is likely to be unfamiliar with this equipment and infrastructure, it is necessary for training programs to include opportunities for staff to become adept in their use. In contrast, infrastructure and equipment required for MCEs are similar to what is routinely utilized in the emergency department, and thus staff is well acquainted with them. This might explain the lack of correlation between infrastructure and equipment with preparedness for an MCE.

\section{Limitations}

Preparedness for radiological events in Israel is based on the doctrine of admitting and treating toxicological casualties. A unique designated doctrine is relevant only to seven referral hospitals. Therefore, the evaluation of preparedness of this specific hazard was not included in the study.

This study does not provide an answer to the extremely important question of how often exercises and drills need to be held in order to assure retention of knowledge and competencies. This should be further investigated, as there tends to be an attrition of knowledge and skills fairly rapidly amongst staff who are not routinely actively involved in emergency management. While the findings of this study present the relationship between hospitals' preparedness for different types of emergencies, the study does not address the degree that preparedness for one type of emergency actually enhances preparedness for other emergency scenarios. Rather than reflecting causal relationships in preparedness across different types of emergencies, it might be that these associations reflect a common causal factor, such as strong leadership and/or strong commitment of the hospital's management towards assuring effective emergency preparedness and response.

\section{Conclusions}

The findings of this study present the relationship between preparedness for different emergency scenarios. There are fundamental critical building blocks such as SOPs, training, and drills programs that improve preparedness for different types of emergencies more than other building blocks, such as equipment or knowledge of personnel. Investing efforts in promoting those components of the preparedness for one scenario may contribute to improved preparedness for other scenarios.

SOPs appear to be an important element in achieving emergency preparedness, especially for emerging scenarios, while knowledge is the basis for managing familiar emergencies. Policy makers should identify the knowledge and skills that are relevant for different types of scenarios, and emphasize them in the training programs.

The findings of this study provide evidence-based support for the all-hazards approach to emergency preparedness, particularly with regard to standard operating procedures, training, and drills. Policy makers in the field of emergency management should discourage the healthcare systems from developing unique designated plans for each type of emergency scenario, but rather focus on identification of similar characteristics of various crisis situations and invest efforts and resources on preparing those components.

\section{Competing interests}

None of the authors had (nor have) competing interests.

\section{Author contributions}

BA designed the study, analyzed the data and drafted the article. AG reviewed the manuscript and provided continuous supervision over the design of the study. RC analyzed the data, edited the manuscript and reviewed it. DL was instrumental in conducting the study. YBD reviewed the manuscript and provided continuous supervision over the design of the study. All authors read and approved the final manuscript.

\section{Funding}

No internal or external funding sources were allocated.

\section{Author details}

${ }^{1}$ Emergency and Disaster Management Division, Ministry of Health, Tel Aviv, Israel. ${ }^{2}$ PREPARED research center, Ben-Gurion University of the Negev, Beer-Sheva, Israel. ${ }^{3}$ Department of Emergency Medicine, Leon and Mathilda Recanati School for Community Health Professions, Faculty of Health Sciences, Ben-Gurion University of the Negev, Beer-Sheva, Israel. ${ }^{4}$ PREPARED Research Center and the Department of Emergency Medicine, The Leon and Mathilda Recanati School for Community Health Professions, Ben-Gurion University of the Negev, P.O.B 653, Beer-Sheva 84105, Israel.

Received: 5 July 2012 Accepted: 21 August 2012

Published: 25 October 2012

\section{References}

1. Sauer LM, McCarthy ML, Knebel A, Brewster P: Major influences on hospital emergency management and disaster preparedness. Disaster Med Public Health Prep 2009, 3(2 Suppl):S68-S73. 
2. Levy LA, Rokusek CF, Bragg SM, Howell JT: Interdisciplinary approach to all-hazards preparedness: are you ready? How do we know? J Public Health Manag Pract 2009, 15(2 Suppl):S8-S12.

3. Taylor L, Miro S, Bookbinder SH, Slater T: Innovative infrastructure in New Jersey: using health education professionals to inform and educate during a crisis. Health Promot Pract 2008, 9(4 Suppl):88S-95S.

4. Godschalk DR, Rose A, Mittler E, Porter K, West CT: Estimating the value of foresight: aggregate analysis of natural hazard mitigation benefits and costs. J Environ Manage 2009, 52(6):739-756.

5. Briere J: Rapid restoration of critical infrastructures: an all-hazards paradigm for fusion centers. Int J Crit Infras 2011, 7(1):21-36.

6. Macintyre AG, Barbera JA, Brewster P: Health Care emergency management: establishing the science of managing mass casualty and mass effect incidents. Disaster Med Public Health Prep 2009, 3(Suppl 1):S52-S58.

7. Watkins SM, Perrotta DM, Stanbury M, Heumann M, Anderson H, Simms E, Huang M: State-level emergency preparedness and response capabilities. Disaster Med Public Health Prep 2011, 5(Suppl 1):S134-S142.

8. Franz DR: Preparedness for an anthrax attack. Mol Aspects Med 2009, 30(6):503-510.

9. White T, Ariaratnam ST, Michael J: Subterranean infrastructure reconnaissance for manmade and natural hazards and disasters. International J Disast Resilience in the Built Environment 2012, 3(1):66-86.

10. O'Brien G, O'Keefe P, Rose J, Wisner B: Climate change and disaster management. Disasters 2006, 30(I):64-80.

11. United Nations Development Programme. Crisis Prevention and Recovery, Disaster Reduction Unit: Reducing disaster risk: a challenge for development. Geneva: UNDP; 2004

12. Von Lubitz DKJE, Beakely JE, Patricelli F: All hazards approach to disaster management: the role of information and knowledge management, Boyd's OODA Loop, and network-centricity. Disasters 2008, 32(4):561-585.

13. Sarpy SA, Warren CR, Kaplan S, Bradley J, Howe R: Simulating public health response to a severe acute respiratory syndrome (SARS) event: a comprehensive and systematic approach to designing, implementing and evaluating a tabletop exercise. J Public Health Manag Pract 2005, 11(6):S75-S82

14. Einav S, Feigenberg Z, Weissman C, Zaichik D, Caspi G, Kotler D, Freund HR: Evacuation priorities in mass casualty terror-related events: implications for contingency planning. Ann Surg 2004, 239(3):304-310.

15. Angelaccio M, Krek A, Catarci T, Buttarazzi B, Dustdar S: WORKPAD: an adaptive peer-to-peer software infrastructure for supporting collaborative work of human operators in emergency/disaster scenarios. International Symposium on Collaborative Technologies and Systems 2006, 173-180. Available at URL: http://ieeexplore.ieee.org/stamp/stamp.jsp? $\mathrm{tp}=$ \&arnumber=1644131\&isnumber=34455".

16. Shugarman LR, Eiseman E, Jain A, Nicosia N, Stern S, Wasserman J: Enhancing public health preparedness: exercises, exemplary practices, and lessons learned. Santa Monica: Rand Corporation; 2005.

17. Leiba A, Goldberg A, Hourvitz A, Amsalem Y, Aran A, Weiss G, Leiba R, Yehezkell Y, Goldberg A, Levi Y, Bar-Dayan Y: Lessons learned from clinical anthrax drills: evaluation of knowledge and preparedness for a bioterrorist threat in Israeli emergency departments. Ann Emerg Med 2006, 48(2):194-199.

18. Vinson E: Managing bioterrorism mass casualties in an emergency department: lessons learned from a rural community hospital disaster drill. Disaster Manag Response 2007, 5(1):18-21.

19. Botoseneanu A, Wu H, Wasserman J, Jacobson PD: Achieving public health legal preparedness: how dissonant views on public health law threaten emergency preparedness and response. J Public Health 2010, 8:1-8.

20. Lovelace K, Bibeau D, Gansnederb, Hernandez E, Cline JS: All-hazards preparedness in an era of bioterrorism funding. J Public Health Manag Pract 2007, 13(5):465-468.

21. Adini B, Goldberg A, Cohen R, Bar-Dayan Y: Relationship between standards of procedures (SOPs) for Pandemic influenza and level of performance in drill. Ann Emerg Med 2008, 52(3):223-229.

22. Wiesman J, Melnick A, Bright J, Carreon C, Richards K, Sherrill J, Vines J: Lessons learned from a policy decision to coordinate a multijurisdiction H1N1 response with a single incident management team. J Public Health Manag Pract 2011, 17(1):28-35.
23. Tan CM, Barnett DJ, Stolz AJ, Links JM: Radiological incident preparedness: planning at the local level. Disaster Med Public Health Prep 2011, 5(Suppl 1):S151-S158.

24. Ricciardi A, Palmer ME, Yan ND: Should biological invarions be managed as natural disasters? BioScience 2011, 61(4):312-317.

doi:10.1186/2045-4015-1-40

Cite this article as: Adini et al.: Evidence-based support for the allhazards approach to emergency preparedness. Israel Journal of Health Policy Research 2012 1:40

\section{Submit your next manuscript to BioMed Central and take full advantage of:}

- Convenient online submission

- Thorough peer review

- No space constraints or color figure charges

- Immediate publication on acceptance

- Inclusion in PubMed, CAS, Scopus and Google Scholar

- Research which is freely available for redistribution

Submit your manuscript at www.biomedcentral.com/submit
C Biomed Central 